\title{
APUNTES SOBRE LA RECEPCIÓN DE LA MÚSICA ABIERTA EN ESPAÑA
}

\author{
Ángel MEDINA ÁLVAREZ \\ Universidad de Oviedo
}

\section{Introducción}

Las publicaciones en torno a la música española de las últimas décadas han aumentado sensiblemente desde hace algunos años. Donde más se ha notado este incremento ha sido en el terreno de las monografías sobre compositores, hasta el punto de que, entre las ya publicadas y aquellas otras que están en fase de redacción, el grueso de los compositores de la Generación del 51 (y algunos de las siguientes promociones) contará con su correspondiente estudio monográfico'. No faltan tampoco visiones generales de esta etapa, ni programas o catálogos con documentación de interés ${ }^{2}$. La propia voz de los compositores se ha dejado oír con frecuencia en numerosas tribunas, habiendo sido recogidos tales autoanálisis -extremadamente irregulares desde una valoración mínimamente crítica - en diversas actas y publicaciones ${ }^{3}$.

Sin embargo, el análisis de la evolución estética de nuestra música no se ha detenido con igual intensidad en cada una de las corrientes que la nutren y que le han dado su actual fisonomía. Así por ejemplo, la recepción del dodecafonismo, por citar una corriente de amplios vuelos internacionales, ha sido ya estudiada con mayor detalle para Cataluña, pero con pinceladas de interés sobre otros lugares ${ }^{4}$.

1. Ciñéndonos a la Generación del 51 existen estudios monográficos —en algún caso más de uno- sobre Cristóbal Halffter, Ramón Barce, Josep Ma Mestres Quadreny, Luis de Pablo, Carmelo Bernaola, Xavier Benguerel, Agustín González Acilu, Antón García Abril y Claudio Prieto.

2. Los Catálogos de Compositores de la Sociedad General de Autores y Editores son actualmente, con su medio centenar de títulos en la calle, los más completos y útiles para gestores, intérpretes e investigadores.

3. Por ser la primera compilación de este género, destacamos: 14 compositores españoles de hoy. Coord.: E. CASARES, Oviedo, 1982. Ethos-Música, $\mathrm{n}^{\circ}$ 9. Publicaciones de la Universidad de Oviedo, Y por su continuidad desde 1988, como tribuna para un buen número de compositores, citamos igualmente los encuentros sobre composición musical, celebrados en Valencia desde 1988 y cuya actas se vienen editando en Publicaciones del Área de Música, IVAECM, Valencia, desde 1989.

4. CaSA Blancas, Benet: "Dodecafonismo y serialismo en España (Algunas reflexiones generales)", Congreso Internacional "España en la Música de Occidente", Salamanca, 1985. Actas, INAEM, Madrid, 1987, vol. II, pp. 413-433. Del mismo autor: "Recepció a Catalunya de l'Escola de Viena i la seva influència sobre els compositors catalans", Recerca musicologica, IV, 1985, pp. 243-283. 
En otra órbita artística, cabe citar al Grupo Zaj, un grupo experimental dedicado preferentemente a la música de acción que, desde mediados de la década de los sesenta, ha generado centenares de artículos de prensa y un número relativamente abundante de aproximaciones más profundas, muchas de ellas de fuerte contenido interdisciplinar; no en vano resulta imprescindible mencionar al grupo Zaj en relación con la introducción y desarrollo en nuestro país del mail art, del happening o de la poesía concreta. La propia personalidad de un grupo que produjo un amplio abanico de manifestaciones artísticas, netamente originales, más allá de la mera integración de determinadas orientaciones internacionales, explica la prolija bibliografía sobre el tema sin que ello desautorice nuestra argumentación, que pudiera hacerse extensiva a otros episodios de la nueva música española.

Por el contrario, la recepción de la música abierta en nuestro país - tendencia que, como se sabe, es común a muy diversas parcelas de la expresión artística a nivel internacional, con fértiles resultados en el campo musical — no ha sido convenientemente estudiada. Los raros y no siempre afortunados párrafos que encontramos en la bibliografía general sobre la música española no son comparables - historiográficamente hablando- con la fortuna crítica de los casos anteriormente citados. Un libro de Tomás Marco, de hace más de un cuarto de siglo, incluye un capítulo específico sobre este asunto que sigue siendo el acercamiento más completo al problema, con mención de buen número de obras y de autores ${ }^{5}$. Y, sin embargo, el fenómeno de la música abierta también suscitó desde los primeros momentos un enorme interés entre los propios compositores, que acabaría traduciéndose en un amplio abanico de teorizaciones de vital importancia para la madurez de la nueva música española.

Las siguientes líneas tienen, pues, el objeto de señalar algunos de los hitos principales en la asunción de los procedimientos de flexibilidad, aleatoriedad y otras formas de la música abierta -y de los compromisos estéticos que ello conlleva - en la música española, incidiendo también en aquellas cuestiones que fueron motivo de preocupación y de reflexión por parte de los propios compositores en los primeros tiempos de dicha asimilación.

Habitualmente se denomina "música aleatoria" a un amplio espectro de creaciones musicales caracterizadas por la intervención del azar, bien en la propia concepción de la partitura, bien en la interpretación global de la misma, o por la presencia de dicho azar en algunos de sus parámetros constructivos o interpretativos. Conceptos como "indeterminación”, "música flexible", "música móvil", junto con determinados aspectos de las técnicas de improvisación, están incardinados en el fenómeno general -y en sentido muy amplio- de la música aleatoria. Sin embargo, la música aleatoria, en sentido estricto, sería uno más entre los fenómenos musicales que, con mayor justificación, se agrupan bajo la denominación de "música abierta". El concepto de "música aleatoria" es una pura metonimia, pues, siendo parte de un fenómeno general, ha

5. MARCo, Tomás: Música española de vanguardia. Madrid, 1970. Guadarrama. 
servido para designar al conjunto de una serie de fenómenos artísticos, emparentados entre sí, pero diferenciables. Del mismo modo que la etiqueta de "pintura abstracta" se empleó por doquier, superando el ámbito de su propia semanticidad, para aludir a fenómenos artísticos perfectamente distinguibles, y ello se hizo desde la crítica hasta el propio humor gráfico, así la "música aleatoria" fue muy pronto membrete socorrido, como sinónimo de realizaciones caóticas o impredecibles, de obras esencial e inquietantemente nuevas ${ }^{6}$.

Ya ha sido señalado por muchos autores que los procedimientos aleatorios no son patrimonio del siglo XX. En pleno siglo XVIII estaban en uso ciertas tablas de composición aleatoria que, naturalmente, no iban más allá del mero juego de sociedad. También se ha dicho que las cadencias concertísticas suponían, en tiempos pasados, un verdadero salto de la condición de intérprete a la de compositor, aunque sea por tiempo limitado, y que el jazz o ciertas músicas extraeuropeas difuminan en muchas ocasiones las líneas de demarcación entre creadores e instrumentistas ${ }^{7}$.

Con todo, el concepto de música abierta está unido a ciertos movimientos del siglo XX y tiene sus más sólidas raíces en los Estados Unidos de América, donde Ives, Cowell, Feldman y Cage, este último como transmisor al mundo europeo de estas concepciones, van a inaugurar una vía que tendrá numerosas ramificaciones y consecuencias para la música de la segunda mitad del siglo XX. Las visitas de John Cage a Europa son decisivas — sobre todo la de 1958 - pero no puede omitirse que las tradiciones europea y norteamericana son muy diversas. Mientras hacia 1950 la vanguardia europea estaba adscrita al serialismo integral, en los EE.UU. de América ya existían partituras con absoluta indeterminación de algunos de sus parámetros constitutivos. En otros términos, la música norteamericana crea realmente la música abierta en su sentido moderno, mientras que la europea tiene que recorrer un camino diverso que, en ocasiones, parte incluso del propio serialismo integral, cuyo control por encima de las propias posibilidades humanas e instrumentales genera precisamente lo contrario de lo pretendido. En consecuencia, los orígenes son distintos, aunque luego confluyan bien avanzada la década de los cincuenta. Por esas fechas, la reflexión de Umberto Eco sobre la obra abierta resulta inseparable de su acercamiento a la música de Berio, Stockhausen, Pousseur y Boulez, quienes provenían de la tradición serial europea y ultrarracionalista ${ }^{8}$.

6. Es muy interesante el análisis de la improvisación en el jazz que sugiere G. Gaslini, en línea con sus conocidos plantearnientos de música total. Tras analizar el compromiso de la vida entera del músico, la puesta a punto de todas sus "capacidades culturales, técnicas y musicales", la implicación de su propia humanidad y la del oyente, asevera: "fuera de dicha 'totalidad' resta sólo sitio para la variación, la aleatoriedad y la apariencia negativa"(el subrayado es nuestro). Líneas atrás afirma: "Alrededor de los años sesenta, el término 'aleatorio' aparecía con mucha insistencia para indicar partituras o proyectos musicales en los que el azar, entendido como 'no programación' constituía el árbitro de determinadas situaciones fónicas, polifónicas o relativas a otros parámetros musicales en el ámbito de la forma". GASLINI, G.: Música total. Barcelona, 1976. Anagrama. pp. 41 y ss.

7. Sobre este tipo de precedentes informan los diccionarios de musicología más habituales. Véase, como ejemplo, las entradas "Aleatory", en The New Grove Dictionary of Music and Musicians. London. Ed. Stanley Sadie, y "Alea-Aleatorio", en Dizionario della Musica e dei Musicisti. Torino. Dir. A. Basso. UTET.

8. Una comunicación a un congreso de Filosofía, titulada "El problema de la obra abierta" es el embrión de su famoso libro Opera aperta (Milán, 1962). El primero de los capítulos de dicho libro se titula "La poética de la obra abierta", y se ejemplifica con creaciones de los cuatro compositores citados. 


\section{El caso de España: pensamiento, realizaciones, marcos organizativos y significación estética}

El objeto de reflexión lo constituye la obra musical abierta. Dejamos a un lado las obras que emplean recursos de azar en su génesis, mas no en su realización sonora, porque entonces prevalece una intencionalidad unívoca, una tendencia a que la obra sea siempre igual a sí misma en las distintas interpretaciones, a la manera de las obras habituales del repertorio y sin que las distintas lecturas de los intérpretes modifiquen la condición unívoca de aquélla y de éstas ${ }^{9}$.

El ámbito del trabajo se circunscribe a la denominada Generación del 51 en cuanto a la selección de compositores, por ser ellos precisamente quienes recepcionaron la corriente que constituye el asunto principal del artículo. En lo temporal arrancamos de 1956 aun cuando la presencia de obras significativas y con algún tipo de proyección se produce en España a partir de 1960. Hacia 1964 puede darse por cerrado el período de asimilación. La reflexión teórica ocupa toda la década de los sesenta.

Es útil señalar, ya de entrada, que la recepción de las músicas abiertas, en el caso español, no se efectúa de forma acrítica, sino que, además de las propias realizaciones musicales, conlleva una reflexión teórica de interés. A este respecto pueden servir de paradigma las concepciones de Ramón Barce, Josep María Mestres Quadreny y Luis de Pablo. Estos tres autores han ido enriqueciendo su pensamiento sobre el fenómeno de la música abierta hasta décadas después de sus primeras intuiciones, lo que contrasta con la anterior asunción de los recursos seriales que resultó (salvo excepciones y con una clara diferenciación geográfica entre Barcelona y el resto de España) mucho más voluntarista ${ }^{10}$.

Si pasamos al ámbito de las realizaciones propiamente musicales, el catálogo se enriquece $y$, junto con los nombres anteriores, que en este extremo no son menos significativos, hemos de contar los imprescindibles de Juan Hidalgo, Cristóbal Halffter, Carmelo Bernaola, entre otros, hasta reunir casi al completo - en los marcos organizativos abiertos a la nueva música- a los sectores más inquietos de la llamada Generación del 51.

El problema terminológico se agrava al centrarnos en el caso español y al indagar con un poco más de detalle en las distintas posibilidades de la música abierta. Ni los compositores ni los musicólogos han llegado a conclusiones estables sobre los aspectos terminológicos.

Casi todas las aproximaciones al tema suelen proponer una especie de taxonomía de las diversas variantes de la música abierta. R. Smith Brindle, por ejemplo, distingue entre la indeterminación parcial y total. En el primer caso afecta a una zona de la obra, o a uno o varios de sus parámetros (altura, duración, expresión, efectivos, espacialidad, forma, etc.). Un caso especialmente interesante se da en la indeterminación de la forma, algo que, como Smith Brindle recuerda, proviene de las artes visuales. Es parcial en cuanto que un número de piezas o partes de una obra (por ejemplo, A,B,C,D) se puede ordenar de varias maneras posibles. El resultado final, en cuanto a la forma es totalmente distinto $(B, A, C, D$, o bien, C, D, A, B, entre otras

9. Al margen de los inevitables factores de inestabilidad que se derivan del propio fluir de la historia y de las circunstancias técnicas. BARCE, Ramón: "Relatividad de la fijación musical”, Atlántida, Vol. I, nº 4, julio-agosto 1963.

10. Vide nota 4. 
posibilidades) pero cada una de esas partes puede estar perfecta y unívocamente construida, sin indeterminación de ningún tipo. Estamos por tanto ante una música de forma abierta, que se plasmó en obras como el Klavierstück XI, de Stockhausen (1956) precisamente una de las citadas en Opera aperta, de Eco. Este es el tipo de concepción que se puede denominar propiamente aleatoria, por cuanto que el azar (no olvidemos el origen del término latino en los juegos de dados) no tiene que ver con el desorden o el caos, sino con la teoría de las probabilidades. Los juegos de probabilidades han de establecerse con entidades precisas, para dar resultados diversos, derivados del azar y estadísticamente analizables. En segundo lugar, la indeterminación se hace total cuando se opera una delegación en el intérprete de las funciones propias del compositor. Bastantes partituras gráficas o textuales - aunque no todas necesariamente - pueden encuadrarse en este segundo bloque ${ }^{11}$.

Ya en el marco de nuestra propia música hemos de citar a Ramón Barce, sin duda el compositor más reflexivo de su generación. Su teorización parte de la psicología de la Gestalt y concibe la forma como: "confluencia de estructura y contemplación", conceptos de "control", "infracontrol" y "supercontrol", que definen las diversas posibilidades de apertura, definidas por la idea de "contorno". Por último, el concepto de "matriz originaria", a modo de arquetipo que nunca se nos va a mostrar totalmente, otorga una dimensión más plena a las obras que asumen decididamente la multivocidad esencial de la expresión musical ${ }^{13}$. La validez de estas premisas es que su articulación permite hablar de toda la gama de tendencias que demasiado irreflexivamente se encuadran en el marco de la música aleatoria. Años atrás, en 1963, otro artículo suyo ${ }^{14}$ recogía un abanico de posibilidades en este terreno, que conviene recordar: 1) Formas temporales variables, 2) Formas combinatorias, 3) Formas flexibles, 4) Música aleatoria, y 5) Formas plásticas y gésticas. Para las músicas aleatorias, en sentido estricto, se requiere un azar - cuyos criterios han sido fijados previamente - y son diferenciadas de las de tipo combinatorio. En las formas gésticas y plásticas se alude a la función especial del intérprete, mientras que la diferencia entre las formas temporales variables y las formas flexibles estriba en los cambios estructurales que pueden darse para el caso de las formas flexibles, frente a las modificaciones moderadas del tempo en las formas temporales variables. Creemos que la terminología que hemos citado en primer lugar es capaz de integrar el conjunto del fenómeno de las músicas abiertas, mientras que la clasificación que acabamos de recoger refleja todavía las dudas de los propios compositores al respecto.

Josep $\mathrm{M}^{\mathbf{a}}$ Mestres Quadreny se preocupó igualmente de estas cuestiones. Al margen de acotaciones puntuales, notas al programa, etc., coetáneas a su primer acercamiento a la cuestión aleatoria, en el sustantivo autoanálisis publicado en el libro 14 compositores españoles de hoy hace memoria de aquellos años pioneros y escribe: "Por aquella época — principios de los años

11. Smith Brindle, R.: La nova música. Barcelona, 1975. Antoni Bosch Ed.

12. BARCE, Ramón: "Música abierta, ventana al infinito", Atlántida, vol. V, n² 29-30, 1967.

13. Hemos analizado su concepción de la aleatoriedad en una monografía sobre este autor, a la que remitimos para mayor detalle. Medina, Ángel: Ramón Barce, en la vanguardia musical española. Oviedo, 1983, Publicaciones de la Universidad de Oviedo. Ethos-Música, $\mathrm{n}^{\circ} 10$.

14. BARCE, Ramón: "La ventana abierta al infinito", La Estafeta Literaria, 14-IX-1963. 
60- se planteó una nueva cuestión, la del fenómeno aleatorio", y tras mencionar la organización generativa de su Quartet de Catroc, de 1962, distingue entre lo que hay de indeterminismo en la obra y el momento en que interviene el azar: "pero el factor que juega el azar en esta obra tiene unas connotaciones muy claras, es decir, la obra saldrá siempre distinta pero siempre de acuerdo con ella misma porque, en este caso, el margen de posibilidades que se le ha dejado es muy limitado, y en realidad su estructura es muy próxima al concepto de móvil" ${ }^{15}$. La diferencia entre la simple indefinición de una obra y la aleatoriedad —en el sentido de cumplimiento de leyes de probabilidad - es tajante en la reflexión de este compositor catalán. Queda claro, por tanto, que la música aleatoria en sentido estricto es un fenómeno bastante limitado. Pero por entonces no se veía como algo tan específico. No en vano, T. Marco se veía obligado a señalar en 1970 que "Io aleatorio se ha convertido en un concepto puro invocado en su descargo por compositores que creen que amparándose en él pueden seguir haciendo desde serialismo hasta soterrado folklore, en la varita mágica que puede dar vía libre a una postura reaccionaria en virtud de su amparo en un slogan de moda. Lo aleatorio puede ser la piel de cordero con que se disfracen los modernos lobos musicales" 16 .

T. Marco propuso en el libro antes citado, de cara al análisis de este fenómeno en España la siguiente triple división: 1) Música móvil, 2) música flexible, y 3) música abierta y grafismo. Las dos primeras no ofrecen problemas conceptuales, pues los móviles ya han sido mencionados, mientras que la música flexible "trata de dar elasticidad al discurso musical, especialmente al rítmico, dentro de un contexto que puede ser móvil o fijo" ${ }^{, 17}$. En cambio, lo que Smith Brindle o Barce agrupan como músicas de improvisación o de sugestión gráfica o literaria, T. Marco lo denomina música abierta y grafismo, señalando que la música abierta es "aquella que contiene un mayor factor de azar o colaboración interpretativa, haciendo hincapié en el grafismo por ser su modo más frecuente de manifestarse, aunque ni mucho menos sea el único" ${ }^{18}$. De forma que, si bien sobre los contenidos de este último apartado no hay demasiado problema, sí se plantea en cuanto a la terminología, pues la acepción de la palabra azar que subyace en la opinión de T. Marco no es la científica (que vimos defendida por Mestres Quadreny con mayor rotundidad) sino la acepción vulgar, en el sentido de simple casualidad y de libertad para posibles soluciones. Estas, a su vez, se plasmarán mayormente no por la propia coherencia del mecanismo aleatorio, sino por las circunstancias casuales e impredecibles de la improvisación o de la hegemonía del intérprete.

Las dos páginas que dedica Manuel Valls a la entrada "aleatoria, música" en su diccionario La música actual no pueden resultar convincentes. Hablar de "formas aleatorias abiertas o móviles" como de una sola cosa resulta especialmente confuso, mientras que equiparar la "alea-

15. Mestres Quadreny, Josep $\mathrm{M}^{\mathrm{a}}$. .: (“Autoanálisis”) 14 compositores españoles de hoy. Coord.: E. Casares, EthosMúsica, $\mathrm{n}^{\circ}$ 9. Publicaciones de la Universidad de Oviedo, 1982.

16. Marco, Tomás: Música española de vanguardia, Madrid, 1970. Guadarrama. p. 125.

17. Ibid.

18. MaRCo, Tomás: op. cit. p. 126. 
toriedad absoluta" a la "libertad absoluta" en el plano interpretativo no es algo que compartan todos los comentaristas ${ }^{19}$.

Como se puede observar, no escasean las propuestas taxonómicas, pero ello no redunda en la clarificación del fenómeno, sino que potencia el lado ambiguo de algunos conceptos y difumina las fronteras entre las diversas posibilidades de obra abierta.

Entendemos que procede hacer un esfuerzo previo de síntesis. Por eso establecemos los siguientes puntos en línea de mínimos:

$1^{\circ}$ Empleamos la expresión MÚSICA ABIERTA como un concepto genérico que agrupa a todas las obras de plasmación esencialmente multívoca. La ambigüedad del término aconseja su uso para referirnos a lo más general.

$2^{\circ}$ Consideramos necesario vincular el concepto de aleatoriedad a una esfera musical analizable en términos científicos, como sinónimo de un determinado tipo de control, proscribiendo el sentido vulgar con que fue ampliamente utilizado. El término no es propiamente ambiguo, como el anterior, sino polisémico. Existe una acepción jurídica y un uso musical metonímico - la parte por el todo-que ya hemos mencionado. Pero es importante señalar que para amplios sectores, dotados de una mínima formación en las disciplinas científicas, el término no está demonizado por el uso arbitrario a que se le ha sometido en el mundo musicaỉ y alude a procesos perfectamente definidos ${ }^{20}$. Los módulos intercambiables según criterios preestablecidos por el compositor o por el intérprete y formantes o los mecanismos combinatorios estrictos son las posibilidades más habituales. La aleatoriedad puede darse en la composición (cuestión que ya dejamos al margen más arriba), en la realización sonora de la obra o en ambas fases del fenómeno musical.

$3^{\circ}$ Podemos hablar de flexibilidad cuando se da una indeterminación en alguno o algunos de los parámetros de la composición. El término vuelve a ser ambiguo, en paralelo con el amplio espectro de posibilidades concebibles entre los apartados extremos de nuestra clasificación. Así, los décalages entre las partes, la opcionalidad de plantilla, la existencia de alturas y/o duraciones indeterminadas en alguna/s zona/s, etc.

$4^{\circ}$ Consideramos que existe indeterminación - término de sentido unívoco-en aquellas obras de máxima multivocidad, como las netamente improvisatorias, frecuentemente servidas mediante escrituras radicalmente ambiguas como el grafismo o la sugerencia textual.

La meditación de los compositores no acaba aquí. Otra notable aportación nos viene de la mano de Luis de Pablo, ahora ya al margen de los problemas terminológicos. En su Aproximación a una estética de la música contemporánea, publicado en 1968, aborda cuestiones harto diversas que, en diferente medida, habían ido nutriendo su propia producción musical, desde más de diez años atrás. Los problemas de la interacción de la macroestructura musical con la microestructura, los conceptos de líneas y puntos, la causalidad total o parcial, y muchos otros temas de gran interés, constituyen una reflexión global sobre la composición, donde no faltan

19. Valls Gorina, Manuel: La música actual. Barcelona, 1980. Ed. Noguer. pp. 50-51.

20. Papoulis, Athanasios: Probabilidad, variables aleatorias y procesos estocásticos. Barcelona, 1980. Eunibar (trad.: Emilio San Vicente Gargallo). 
apartados en torno a la música aleatoria ("o abierta, en movimiento, flexible, etc...”) ${ }^{21}$. Así, epígrafes que estudian la causalidad total y parcial, los tipos de libertad compositivos, las macroestructuras determinadas con microestructuras libres (y viceversa) la movilidad interna de la música, la alternancia de partes móviles y fijas y, en fin, la negación de la propia obra con la indeterminación de las macro y las microestructuras - como caso típico de "sustitución de voluntades"- constituyen referencia inevitable en este abanico de reflexiones teóricas que, como se ve, tienen una talla intelectual que no se dio en la recepción previa de otras novedades de la creación musical contemporánea ${ }^{22}$."El compositor aleatorio - había dicho De Pablo años atrástal y como yo lo entiendo, tal y como yo lo quisiera practicar, es el compositor que desocupa - como diría el escultor español Jorge Oteiza- el espacio habitable de la obra y da la posibilidad al auditor de ocuparlo - estableciendo una comparación un tanto cómica - tanto bien sea un comedor, como un living-room"23.

Como era de esperar - y lo consideramos como un síntoma de buena salud intelectualhubo también algunas opiniones contrarias. Quizá la más destacable sea la de Oscar Esplá. Con las convicciones de su juventud intactas, como un nuevo Jacobo de Lieja (perplejo y crítico en su Speculum Musicae ante un Ars Nova que le ofrecía más posibilidades pero menos plenitud que los antiguos motetes del siglo XIII) así Esplá se rebela ante unas músicas dotadas acaso de "inteligencia conceptual", pero desprovistas de la necesaria "inteligencia afectiva" y más cercanas al "entretenimiento acústico" que a la verdadera obra de $\operatorname{arte}^{24}$. A veces alude a la música abierta de manera genérica y harto imprecisa, quizá ampliando el concepto hasta incluir cualquier tipo de experimentalismo. También introduce Esplá una valoración cuyo sentido no se percibe hoy perfectamente: "En el criterio que suele informar la música abierta vemos una chocante transposición de nociones: lo social artístico se convierte en societario-económico-político". ${ }^{25}$ Sin embargo, Esplá está apuntando contra cierto gusto socializante que buscaba también su plasmación en una cierta corresponsabilidad entre los diversos eslabones de la cadena artística. Un planteamiento como el de la música abierta, con su posible delegación en los intérpretes, resultaba inaceptable para un autor formado en una tradición donde los conceptos de artista y obra comportan un alto grado de individuación. Tampoco descarta Esplá la ironía para referirse a la ambigüedad terminológica ${ }^{26}$, ni cuando critica la hipertrofia notacional y afirma que se llega a "una tal indeterminación musical que, con sus signos puede interpretarse lo mismo La Traviata que la Divina Comedia o las Pirámides de Egipto",27. Acto seguido arremete contra las obras fabricadas "con piezas de recambio" que, a la postre, definen "tantas obras distintas como

119.

21. PABlo, Luis de: Aproximación a una estética de la música contemporánea. Ed. Ciencia Nueva, Madrid, 1968, p.

22. PABLo, Luis de: op. cit. pp. 117 y ss.

23. "Coloquio sobre la música contemporánea", I Conversaciones de Música de América y España. I Festival de Música de América y España. Madrid, 1970. Dirección General de Música. pp. 43 y 44.

24. EsPlá, Oscar: "Consideraciones sobre las tendencias de la música contemporánea”, en I Conversaciones de Música de América y España. I Festival de Música de América y España. Madrid, 1970. Dirección General de Música. p. 28.

25. EsPlá, O.: op. cit. p. 50, párrafo 2.

26. EsPLÁ, O.: art. cit. p. 52, párrafo 2, música "abierta o entornada".

27. ESPLÁ, O.: art. cit. pp. 52-53. 
sustituciones, recambios o elecciones, ya que en arte no existe un fondo independiente de la forma" ${ }^{28}$. El tono irónico del compositor levantino no vela la gravedad del problema. La cuestión toca directamente en la línea de flotación de conceptos sacralizados por la tradición romántica. Afecta de lleno al papel del compositor en la sociedad contemporánea. Ramón Barce ya lo había diagnosticado en un breve e interesante trabajo de $1963^{29}$. Tras desmontar el mito de la inmutabilidad de la obra de arte, cuya falacia en el caso de la música es evidente ante "la imposibilidad por parte del ejecutante de reproducir con exactitud y coherencia relativa matemáticas los signos

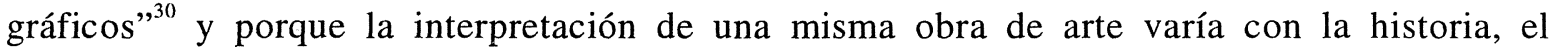
compositor se pregunta entonces si merece la pena esforzarse en conservar "la identidad consigo misma de la obra musical, si ambos factores -el matemático y el histórico- relativizan inexorablemente tal estabilidad",31. En la respuesta que da el propio compositor palpamos el sentido épico que habita en toda inquietud vanguardista, la convicción de estar haciendo algo realmente nuevo y distinto: "De esta pregunta - aterradora para un artista - ha surgido todo un arte nuevo. Porque el compositor ha decidido que la única manera de resolver el problema era la más arriesgada, la más heroica, y al mismo tiempo la más lógica: asumiéndolo, incorporándolo" 32 . Como se ve, la secular y repetida lucha entre el cambio y la estabilidad, entre lo nuevo y lo viejo, tiene en los años sesenta del siglo XX este modesto pero atractivo episodio hispánico.

A modo de simple muestreo, pues el análisis de la producción de música abierta en España sería más bien objeto de un amplio ensayo, señalamos algunas aportaciones de los compositores que hemos venido citando. Desde una óptica individualizada resulta imprescindible citar en primer lugar al compositor canario Juan Hidalgo, vinculado a los más importantes centros generadores de novedades musicales, como Milán o Darmstadt. Autor de importantes textos creativos o de poética artística, su perfil compositivo se manifiesta sobre todo en la acción, en la inquietud de una obra, pionera siempre, donde el arte y la vida han acabado por fusionarse indeleblemente. Es así como se explica que en Ukanga, de 1957, ejemplo clásico de serialismo integral, aparezca un piano preparado, "que faculta una renovación, siquiera sea parcial de la obra a cada audición", tal como señala T. Marco. Otras obras de Hidalgo (Offenes Trio, Ciu-Quartett Music), estrenadas al año siguiente en Milán, se erigen igualmente en adelantadas de diversas formas de la música abierta, entre ellas la propia música gráfica.

Ya en España, y antes de que concluya la década, cabe recordar las aportaciones de Luis de Pablo, con obras como Móvil y Progressus, cuya fecha T. Marco ha fijado en 1959, y no un año antes, tal como figura en la edición de Tonos Verlag ${ }^{34}$. Sin embargo, el biógrafo más autorizado de este compositor, José Luis García del Busto, sitúa la génesis de esta obra en 1957, en relación con una solicitud de la pianista Margot Pinter. Este mismo autor nos recuerda que

28. ESPLÁ, O.: art. cit., p. 53.

29. BARCE, Ramón: "Relatividad de la fijación musical", Atlántida, Vol. I, n 4, julio-agosto 1963.

30. BARCE, Ramón: art. cit. p. 2 (423).

31. BARCE, Ramón: art. cit. p. 3 (424).

32. Es el paso que hay entre creer en lo "sedicentemente absoluto" y aceptar lo "explícitamente relativo". art. cit. p. 3

(424).

33. MARCo, Tomás: Música española de vanguardia, Guadarrama, Madrid, 1970, p. 90.

34. Marco, Tomás: op. cit. p. 12. 
incluso con anterioridad a esta fecha, en Comentarios, de 1956, es en donde L. de Pablo "inició la andadura en el resbaladizo mundo de la aleatoriedad" No perdamos de vista - a efectos del indispensable rigor en el análisis histórico- que la proyección de Juan Hidalgo, por entonces, en función de sus experiencias internacionales, era mucho mayor que la de L. de Pablo, quien, por otra parte, no estrenaría esta última obra hasta 1960. De forma que si la fecha de 1956 correspondiente a la composición de Comentarios es significativa -y mucho - en el catálogo de este compositor, en lo que atañe a su propia aproximación a la música flexible y, desde luego, en los anales de la historia de la música española contemporánea, ya no lo es tanto en términos de recepción general de la corriente que estamos analizando.

Por entonces, De Pablo iba a ir perfilando su aportación creativa más trascendente a este respecto. Se trata de los "módulos", término que aparece en el título de varias de sus obras y que, como elemento de estructuración, subyace en otras muchas de su catálogo. No podemos extendernos en ellos, pero sí reiteramos su carácter basilar, por una parte, y el hecho de que si, como señala T. Marco en un interesante análisis sobre este concepto, los módulos "están conectados en alguna manera con el serialismo integral, que es un sistema de composición rígida, lo están en la misma medida con los sistemas de composición aleatoria" "36. Obras como Radial, de 1960, el Libro para el pianista, o su importante Polar, éstas de 1961, y muchas otras a partir de ese momento, muestran las soluciones que el peculiar ingenio compositivo de Luis de Pablo fue lanzando respecto al fenómeno de la música abierta.

El caso de Mestres Quadreny resulta especialmente interesante. Su formación científica no es ajena a la incorporación en su música de procedimientos matemáticos, estadísticos e informáticos. Su aprecio de las artes plásticas, en especial de las esculturas móviles o la arquitectura modular también está en la base de sus constantes realizaciones de tipo aleatorio. Desde obras que incluyen el azar — matemático — en su génesis, pero que son de intencionalidad unívoca de cara a la interpretación, hasta indeterminaciones parciales, o planteamientos combinatorios y asunción plena de la obra abierta en su etapa de audición, Mestres Quadreny tiene un amplísimo surtido de obras donde la construcción aleatoria es absolutamente decisiva en la ideación estética de la partitura. Aunque fuera del marco fijado, mencionaremos su gran obra de balance en este terreno, titulada expresivamente como L'Estro aleatorio, constituida por seis conciertos de los años 1973 a 1978, impensable sin sus preocupaciones de bastantes años atrás, plasmadas en obras como Invencions Mòbils, de 1961, o Tramesa a Tàpies y el Quartet de Catroc, ambas de $1962^{37}$.

35. García del Busto, José Luis: Luis de Pablo, Espasa Calpe. Madrid, 1979, p. 31 y ss.

36. Marco, Tomás: "Los módulos", en Escritos sobre Luis de Pablo, Taurus, Madrid, 1987. p. 165.

37. Numerosos párrafos y, muy en especial, los capítulos IV y V del ensayo de Ll. Gasser sobre Mestres Quadreny prueban la relevancia de lo aleatorio en la obra de este último. GASSER, Lluis: La música contemporánea a través de la obra de Josep Ma Mestres Quadreny. Ethos-Música, 11. Publicaciones de la Universidad de Oviedo, 1983. 
J. Ma Mestres Quadreny: Quartet de Catroc, 1962 (Particela de violín 1. ${ }^{\circ}$ )
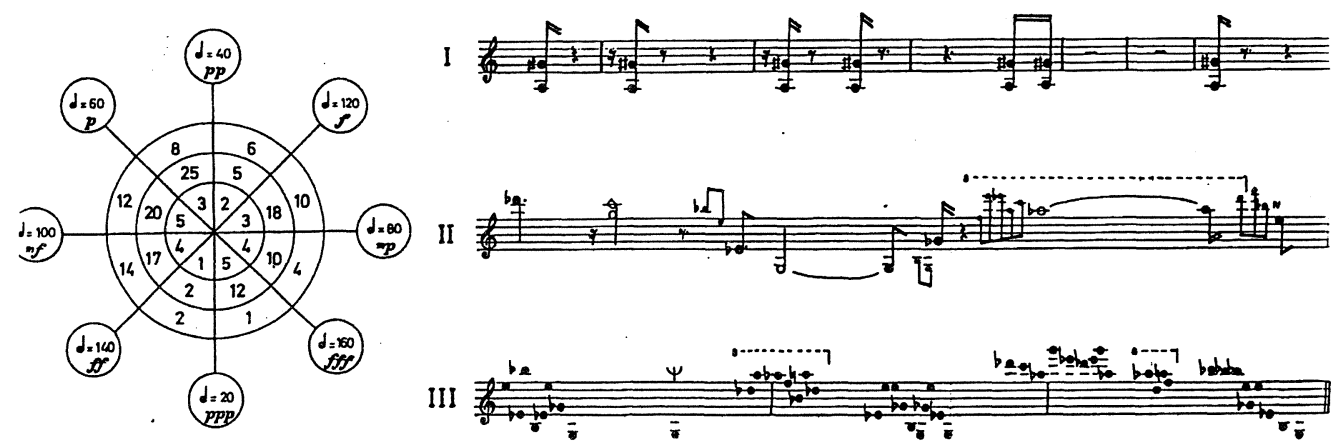

Un uso muy limitado, pero extremadamente sugerente de las posibilidades de la música abierta, es el que encontramos en algunas creaciones de Ramón Barce. Desde la flexibilidad moderada de obras como el Estudio de sonoridades, de 1962, y la lograda síntesis que se opera entre elementos de control dinámico y flexibilidad de duraciones en Parábola, un quinteto de viento, de 1963, o en los Objetos sonoros, de ese mismo año, Barce llegaría a construir obras más plenamente abiertas, profundizando en una controlable independencia temporal de los ejecutantes, o del solista frente a la orquesta - Canadá Trío, Concierto para piano y orquesta, de la siguiente década - que no entorpecen su fundamental preocupación armónica o sistema de niveles. Pero como compositor de amplias inquietudes intelectuales, ha de citarse igualmente por su Síntesis de Siala, una obra de 1965, ejemplo radical de la música de sugestión gráfica en España y de los máximos niveles de delegación de responsabilidades en los posibles intérpretes de la obra $^{38}$.

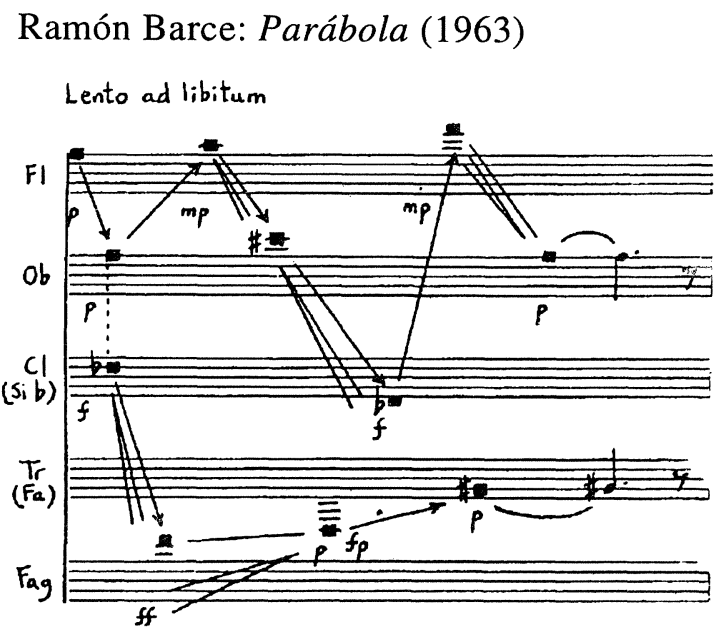

38. Medina, Ángel: Ramón Barce, en la vanguardia musical española. Ethos-Música, 10. Publicaciones de la Universidad de Oviedo, 1983 (Principalmente el capítulo II) 
Cristóbal Halffter, por tantos motivos figura señera de su generación, fue también sumamente cauteloso respecto a la música abierta. Crítico con el novedoso concierto de David Tudor de 1960, al poco tiempo admite, respecto a su obra Formantes, móvil para dos pianos, que "con ella entra en mí algo que ya llevaba preocupando a algunos compositores de mi generación" ". Esta obra (que presenta una movilidad de los seis formantes centrales y mantiene fijos el primero y el último) se estrenó en abril de 1961, pero tuvo además una notable proyección internacional, por su interpretación en el festival de la SIMC de 1962, en Londres. En la Sinfonía para tres grupos instrumentales prosigue Halffter su asimilación de las formas abiertas, siempre dentro de un marco de control por parte del compositor y siempre integrando esta preocupación en lo que ya por entonces eran sus constantes artísticas de expresividad y rigor formal, aquí elaboradas en torno a los problemas de la densidad sonora. El paso a la técnica de anillos, desde su obra Espejos, cuyos orígenes datan de 1963, demuestra que, sin hacer de la cuestión aleatoria un problema en sí, C. Halffter puede integrarla, en sus niveles más radicales y hasta el tiempo presente, como uno más de los medios posibles para el logro de su desbordante expresividad.

Algo similar, en cuanto a fechas, prudencia en la asimilación e integración en el propio lenguaje, se detecta en la música de Carmelo Bernaola. Finalizada en diciembre de 1961, Superficie $n^{o} 1$ tiene ya detalles de "indudable sesgo aleatorio" ${ }^{40}$, como apunta A. Iglesias, pero hay que esperar al año siguiente, con la obra Espacios variados ${ }^{41}$, para encontrarnos con espacios temporales flexibles y posibilidades de intercambio en el orden de sucesión, movilidad y flexibilidad que también se plantean en Morfología sonora, de 1963 y que desde entonces acompañarían a mucha de la mejor música de este compositor.

T. Marco ha reseñado otros nombres y otras creaciones de valía en el campo que estamos analizando. Por ejemplo, Enrique Reaxach, con Fluxion, de 1963, o Gonzalo de Olavide, con Índices, del año siguiente -esta última con una atrevida e inusitada flexibilización de los propios efectivos instrumentales - han de sumarse igualmente al haber de este tipo de producciones ${ }^{42}$. Entendemos, sin embargo, que procede cerrar aquí este muestreo, para esbozar unas líneas en torno a algunas iniciativas que encauzaron y difundieron esta nueva orientación de la música española, colaborando con su entramado organizativo en la elevación del nivel de debate y en una mayor receptividad por parte del público.

En términos colectivos o, más bien, de grupos de creación u organización musical, se advierte un comprensible retraso en el debate. Pero de nuevo volvemos a insistir en la mejora de nivel respecto a unos pocos, muy pocos, años atrás.

39. Recogido en Casares Rodicio, Emilio: Cristóbal Halffter, Ethos-Música, 3, Publicaciones de la Universidad de Oviedo, 1980, p. 88.

40. IgLeSiAS, Antonio: Bernaola, Espasa-Calpe, Madrid, 1982, p. 82.

41. El estreno en el Palau barcelonés estuvo teñido de polémica, pues a la novedad de la obra y al propio conservadurismo de ciertos sectores del público, se sumó una nota de la agencia Cifra en la que, según refiere su biógrafo, se llegó al insulto y a la descalificación personal, lo que no puede dejar de mencionarse como hito significativo, aunque sea por negación, en la asimilación de las nuevas músicas en España. Iglesias, A.: op. cit. pp. 86-87.

42. MARco, Tomás: Música española de vanguardia, Guadarrama, Madrid, 1970 (consúltese especialmente el capítulo VIII, que constituye una encomiable aportación a esta problemática, por su abundante mención de obras, autores, agrupados en las tendencias generales previamente definidas por el autor, y con datos que se introducen ya en las promociones subsiguientes a la Generación del 51). 
En 1987, con motivo de la presencia de Juan Hidalgo y de W. Marchetti en la III Mostra de la Música Catalana, el libro-programa incluye un texto titulado "Un homenaje al Club 49 de Zaj" donde se señala que habiendo llegado estos dos compositores a Barcelona, a fines del 58, procedentes de Gran Canaria, hicieron entrega al poeta Joan Brossa de una carta de Millares, iniciándose un contacto que, una vez ampliado hasta la respetada figura de Prats, cristaliza en un concierto para dos pianos de cola y otros objetos, como base de lo que habría de ser Música Abierta. Este fue un concierto, que Marco llama "preliminar", al que seguiría la redacción de un manifiesto de Hidalgo sobre la música aleatoria con motivo del segundo concierto, considerado como fundacional. De acuerdo con Mestres Quadreny, tuvo lugar el 11 de mayo de 1960 y participaron intérpretes de la talla de Pedro Espinosa y Anna Ricci, junto con otros instrumentistas, todos dirigidos por Jaume Bodmer. En el programa, obras de Homs, Cercós, De Pablo (la ya mencionada Comentarios), Hidalgo y Mestres Quadreny.

Aunque el Club 49 - del que formaban parte personalidades de la cultura y el arte de Cataluña, como Prats, Miró, Tàpies, Homs, entre otros- ya había organizado sesiones musicales mediante grabaciones - y más escasamente en directo- desde 1952, el nuevo contenido y modernidad que abre la década de los sesenta lleva a enmarcarlos en la expresiva denominación de Música Abierta.

Música Abierta, funcionó eficazmente de 1960 a 1968, fecha esta última en la que se plantearon iniciativas de mayor envergadura, que reflejaban además la salida a la luz pública de las experiencias musicales vanguardistas, tras ocho años de verdadero - pero minoritarioesfuerzo organizativo. Los conciertos y conferencias, en número de cincuenta aproximadamente, nutrieron durante estos ocho años al público barcelonés menos conformista, objetivos conseguidos con la ayuda de los Institutos Francés, Alemán e Italiano y el apoyo de las personalidades antes citadas y los organizadores específicos de las sesiones, Homs, Hidalgo y Mestres Quadreny.

Con todo, la continuidad en el empeño - ya que Hidalgo no permanecerá en Barcelona, y por tanto los planteamientos decididamente vanguardistas del compositor canario quedarán tamizados por otras tendencias - se debe a Mestres Quadreny. Este compositor, en su ensayo antes citado y refiriéndose a Música Abierta, escribe: "Es difícil hacer una valoración de lo que significaron estos conciertos ya que por su carácter semiclandestino no podrían incidir sobre el gran público y solamente la lenta relajación de la dictadura facilitó al final, sobre todo en el ciclo Música d'avui al Tinell, el darles una proyección más ambiciosa. Por lo menos permitió a los interesados mantenerse al corriente de las novedades que se producían en el extranjero y permitió a nuestros compositores más abiertamente renovadores (Homs, Cercós, Delás, Mestres Quadreny, etc.) presentar algunas de sus obras"

El ciclo mencionado por Mestres Quadreny fue el origen de las nuevas y más amplias vías de desarrollo de la música vanguardista en Barcelona, al tiempo que broche de oro para una actividad concertística que introdujo los nuevos conceptos musicales en el panorama musical

43. Mestres Quadreny, J. Ma.: "La nueva música catalana en los últimos 30 años", en 14 compositores españoles de hoy, Ethos-Música, 9. Publicaciones de la Universidad de Oviedo, 1982, pp. 379 y ss. 
catalán. El medio centenar de actos realizados durante estos ocho años otorgan a Música Abierta un lugar de privilegio a la hora de reconstruir la historia de la nueva música en el ámbito catalán, pero marcando hitos igualmente para el conjunto de la moderna historia musical española.

Es digno de mención que aunque el nombre de esta sección del Club 49 parece inclinarse por una tendencia determinada de la música de los años sesenta, lo que incluso parecía lema de manifiesto artístico, el concepto de "música abierta" también tiene una parte de tolerancia, de apertura — como señala Mestres Quadreny- hacia "todo lo que se produjese realmente nuevo, sin limitación de estética, de ahí el nombre de Música Oberta"44. El propio Juan Hidalgo definía su proyecto como "música abierta, música activa, del ayer próximo, del hoy y del mañana". Es así que, si bien los contenidos de esta sección del Club 49 no se ciñeron exclusivamente a las creaciones abiertas y/o aleatorias, no es menos ciertos que precisamente éstas tuvieron allí un magnífico campo de cultivo y de discusión.

No obstante, el momento decisivo por su trascendencia y novedad objetiva, y por su eco en la crítica de las dos grandes capitales españolas, tuvo lugar con la intervención del pianista $D$. Tudor, en Barcelona y Madrid, merced a las gestiones de la Asociación de Diplomados del Instituto de Boston, en noviembre de 1960. La asimilación de dicho concierto no resultó fácil. Críticos y comentaristas de renombre, como Valls Gorina, reaccionan con recelo cuando no con inusitada violencia dialéctica. Enrique Franco, desde las páginas del diario Arriba ${ }^{45}$, analiza el concierto de David Tudor (con obras de Nilsson, Marchetti, Wolft, Hidalgo, Bussotti, Ichiyanagi y Cage) salvando apenas algunas obras y asestando un duro golpe al experimentalismo propuesto en el concierto. Valls, por su parte, primero en la prensa diaria y posteriormente en un libro, valioso por otros motivos ${ }^{46}$, se muestra francamente beligerante y también avisa sobre el posible snobismo de la vanguardia más experimental.

Tomás Marco ha señalado la importancia de estos acontecimientos, indicando su anterioridad a las actividades de Tiempo y Música, de L. de Pablo y lo que supuso como balance histórico de una vanguardia que, muy poco antes, había conocido las novedades de Darmstadt y que tenía que dar respuesta a los interesantes problemas estéticos planteados por la música abierta en sus diversas especialidades.

Un jalón importante en todo lo concerniente al recibimiento de las músicas aleatorias en España va a tener lugar en Madrid, en el seno del Aula de Música del Ateneo de Madrid desde 1961. Este año, el 17 de mayo, entre otras actividades, se presenta en público la obra Formantes, móvil para dos pianos, de C. Halffter, emblemática en cuanto a la historia puntual de la música abierta en España. En marzo de 1961 La Estafeta Literaria incluía una especie de editorial sobre la música abierta, de F. Ruiz Coca ${ }^{47}$, que compartía página con un análisis de Klavierstück XI, obra de Stokhausen ya citada, firmado por C. Halffter ${ }^{48}$.

\footnotetext{
44. Ibid.

45. Franco, Enrique: "David Tudor presenta un programa de música experimental". Arriba, 12-XI-1960.

46. Valls Gorina, Manuel: La música española después de Manuel de Falla. Ed. Revista de Occidente, Madrid, 1962.

47. Ruiz Coca, Fernando: "Música abierta" La Estafeta Literaria, 1-III-1961.

48. HalfFTER, Cristóbal: “Klavierstück-XI, de Stockhausen”, La Estafeta Literaria, 1-III-1961.
}

[14] 
El curso 62-63, sin embargo, aún va a resultar más relevante en este aspecto, pues el Aula organiza un ciclo sobre la música abierta. Habida cuenta de la estrecha colaboración de la prestigiosa revista La Estafeta Literaria con el Aula de Música, a través de F. Ruiz Coca, el número correspondiente al 14 de noviembre de 1963 recoge una parte de las opiniones y debates habidos en relación con el tema de estudio, constituyéndose en un documento de gran valor para conocer de primera mano la madurez con que los compositores españoles integran este fenómeno artístico ${ }^{49}$. Un amplio editorial del crítico Ruiz Coca señalaba: "Las 'formas abiertas' son hoy así el caballo de batalla de la creación musical", , añadiendo acto seguido algunas consideraciones que merece la pena transcribir, por cuanto que ilustran la manera en que las músicas abiertas iban pasando del círculo de iniciados de los críticos y compositores al público en general, al tiempo que se deja constancia del carácter pionero y sistemático de la susodicha reflexión de conjunto sobre el tema: "El Aula de Música del Ateneo de Madrid, siempre atenta a las novedades significativas que la aventura del arte vivo depara en cada encrucijada, dedicó durante el curso pasado un ciclo de estudios a este apasionante temario. En el reducido ámbito de su seminario primero, en las sesiones públicas del Aula después, fue examinado este capítulo de la estética de nuestro tiempo por un grupo de compositores, interesados no sólo como fríos analistas de partituras, sino desde el punto de vista de creadores implicados de lleno en el movimiento (...) La voz de nuestros músicos, vigente en Europa sin recurrir a la formulilla de lo pintoresco, ha tenido un valor de plena actualidad, planteando por primera vez en España, de una forma sistemática, el problema",51.

El año 1964 resultaría, como es de sobra sabido, muy fecundo para las nuevas iniciativas. Surge Zaj. Se organiza la Bienal de Música Contemporánea y el ya citado Festival de Música de España y América. También en la Bienal la "cuestión aleatoria" suscitó animados debates con presencia de grandes creadores internacionales. Mas no se trataba de los primeros tanteos propios de los momentos de recepción, sino de una delimitación de posturas estéticas que sólo resulta explicable en un estadio de sedimentación y de madurez. Este año es como un torbellino para la nueva música: las ideas fluyen, la atracción de Darmstadt y otros centros europeos continúa - pero sin la fe ciega de pocos años atrás ${ }^{52}$ - y la apertura hacia América continuará hasta el final

49. Además del editorial de Ruiz Coca, que citamos en la nota siguiente, destacamos: BARCE, Ramón: "La ventana abierta al infinito"; CARRA, Manuel: "Factores aleatorios en las formas temporales"; HaLfFTER, Cristóbal: "Cabe la creación en la música abierta"; Mestres Quadreny, Josep M".: "Dos ejemplos: Sensitivo y Quartet de Catroc", todos ellos en La Estafeta Literaria, 14-IX-1963.

50. Ruiz CocA, Fernando: "Nueva problemática musical: sobre las formas abiertas", La Estafeta Literaria, 14-IX-1963.

51. Ibid. Más información sobre el Aula de Música en Medina, Ángel: "Oleadas vanguardistas en el área de Madrid". Actas Congreso Internacional España en la Música de Occidente. Madrid, 1987. INAEM.

52. El crítico Enrique Franco, en mayo de 1961, tras calificar a Darmstadt como "Meca de las últimas promociones musicales europeas", describe así el "fenómeno Darmstadt": "meca hacia la que apuntan las aspiraciones de músicos de todos los países y, en realidad, razón para el encuentro, el estudio, el análisis, la toma de contacto de quienes, más o menos, persiguen un dial análogo: encontrar el significado musical de nuestro tiempo" Franco, E.: "Los compositores españoles y Darmstadt", Arriba, Madrid, 20-V-1961 En Darmstadt —escribe el compositor Ramón Barce - "se asiste materialmente a la gestación y nacimiento de la música de nuestro tiempo: es como un volcán en cuyo fondo pudiéramos ver la lava en ebullición". BARCE, R.: "Darmstadt, última hora de la música", La Estafeta Literaria, Madrid, 1-XI-1961. Este compositor ha modificado sustancialmente su valoración a este respecto, en tono extremadamente crítico, como se puede comprobar en MEDINA, Ángel: "Intrivista a R. Barce. Una voce meditativa nella musica spagnuola", Musica/Realità nº 33, XII-1990, pp.133-146. Trad.: Roberto Tonetti. Milán. 
de la década ${ }^{53}$. El problema ya no es, en 1964, la asimilación de lo nuevo, sino la ubicación estética de cada compositor en las no siempre despejadas provincias de la creación musical. Es también el momento de la inflexión, que reconduce a determinados pioneros de la Generación del 51 hacia problemas de comunicación y de psicología de la percepción y hacia la búsqueda de lenguajes y sistemas propios. Y es, en fin, la fecha en que las siguientes promociones se empiezan a dar a conocer con obras donde los elementos de lenguaje abierto se integran con normalidad.

Lo que resulta innegable es que, $1^{\circ}$ ) coincidiendo con las continuadas actividades del Ateneo de Madrid y las puntuales pero muy intensas de los citados eventos de 1964 los compositores españoles podían ya ofrecer al público obras fundamentales en términos de lenguaje abierto; $2^{\circ}$ ) que, del mismo modo, se habían lanzado a la teorización sobre el particular, reflexión que se prolongaría, en sus mejores aportaciones, hasta tiempos muy posteriores; y $3^{\circ}$ ) que, por último, la acogida en sendas entidades de Madrid y Barcelona, junto con algún evento sorprendente, con tintes de escándalo artístico, había generalizado el interés por la cuestión aleatoria en amplios sectores del mundo musical y lo había extendido entre el minoritario público de la música contemporánea. La recepción había concluido, sentando las bases de nuevos capítulos de nuestra historia musical cuyas realizaciones llegan hasta el presente. 